\title{
Octavio Paz y la modernidad: Una crítica vanguardista desde los suburbios de la civilización
}

\author{
Octavio Paz and modernity: \\ An avant-gardist criticism from the suburbs of civilization
}

Xavier Rodríguez Ledesma*

\begin{abstract}
Resumen: Desde los años cincuenta del siglo pasado, una voz latinoamericana comenzó a llamar la atención sobre la necesidad de pensar el significado de la modernidad en términos generales y, específicamente, de la forma en que desde estas regiones alejadas de las metrópolis habríamos de resignificarla para, recuperando nuestra especificidad, construir caminos propios y distintos por los cuales avanzar. Ella era la voz de un poeta, no de un científico social ni de un filósofo. Desde hace apenas algunas décadas la reflexión sobre la modernidad se ha convertido en un tópico dentro del ámbito académico y cultural mundial, y llama la atención que aquellas profundas y vanguardistas disquisiciones sean desconocidas o, de plano, ninguneadas por los centros y discursos hegemónicos del saber. El autor de esa riquísima, profunda, sugerente, vanguardista y bien escrita reflexión sobre la modernidad fue el poeta mexicano Octavio Paz.
\end{abstract}

Palabras clave: Octavio Paz; modernidad; Latinoamérica

Abstract: Since the fifties of the last century, a Latin American voice began to call attention to the need to think about the meaning of modernity in general and, specifically, how we could give it a new meaning in remote regions, far from the metropolis - and, by doing so and recovering our specificity, find our own ways to reach our own, specific destination. It was the voice of a poet, not of a social scientist or a philosopher. Since few decades, reflection on modernity has become a topic within the academic and cultural world; it is surprising that those deep and avant-gardist digressions are unknown or just denied by the hegemonic centers and discourses of knowledge. The author of this rich, deep, inspiring, avant-gardist and well-written reflection on modernity was the Mexican poet Octavio Paz.

Keywords: Octavio Paz; modernity; Latin America

* Doctor en Ciencia Política por la Unam, investiga políticas educativas para la diversidad, historia y sociología de la cultura en el México contemporáneo y enseñanza-aprendizaje de la historia. Es professor e investigador en la Universidad Pedagógica Nacional, México. Publicó, entre otros, Una historia desde y para la interculturalidad (2008), Silencios intelectuales: la crítica en tiempo de crisis (2009), Escritores y poder. La politica frente al espejo de tinta (2008).<conequis@hotmail.com>.

\begin{tabular}{|l|l|l|l|l|l|}
\hline Civitas & Porto Alegre & v. 12 & n. 1 & p. 161-177 & jan.-abr. 2012 \\
\hline
\end{tabular}


La modernidad me acompaña desde que comencé a escribir. Sus espejismos y sus realidades, sus vértigos y sus dádivas inesperadas, son parte de mi biografía intelectual y poética.

Octavio Paz

Hoy en día a trece años de la muerte de Octavio Paz, alejada ya un poco de los conflictos y polémicas que ensombrecieron su claridad, su obra política comienza a ser evaluada desde otras perspectiva aún por sus detractores. Con ello es posible resaltar un curioso y significativo fenómeno cultural: a pesar de que la reflexión crítica (política y filosófica) en la obra paciana es altamente valorada, ésta continúa padeciendo el ninguneo histórico que el ser producto de un autor nacido en un país de las afueras de la modernidad le imprimió.

El haber obtenido el premio Nobel de Literatura en 1990 no elimina la sentencia recién señalada, al contrario. La obtención del máximo galardón mundial de las letras evidencia en toda su carga discriminatoria el hecho de que en el stablishment académico y cultural las reflexiones de Paz sobre la modernidad (otredad, pluralidad, diversidad, tolerancia, tiempo, etc.) sean completamente desdeñadas en las discusiones contemporáneas que abordan esos temas de moda sobre los cuales el poeta mexicano reflexionó desde los años cuarenta del siglo $20 \mathrm{y}$ hasta sus escritos finales con asombrosa lucidez. ${ }^{1}$

Paz lo sabía y el asunto le enfadaba. Aunque en escasas ocasiones él no dejó de lamentar que por ser un intelectual mexicano que escribía desde Latinoamérica, su voz carecía de la caja de resonancia reservada para los intelectuales europeos, quienes acaparaban las "pláticas familiares" sobre la razón de ser y la condición de las sociedades avanzadas, sus sociedades, no las nuestras. ${ }^{2}$

Su crítica - filosa y a contracorriente - sobre el socialismo realmente existente paulatinamente se fue haciendo, a partir de los años cincuenta,

\footnotetext{
1 Al respecto Pascale Casanova afirma: "El carácter irremediable y la violencia de la escisión entre el mundo legítimo y sus arrabales sólo son perceptibles para los escritores de las periferias que, teniendo que luchar muy concretamente para 'encontrar la puerta de entrada', como dice Octavio Paz, y para hacerse reconocer por el (o los) centro(s), son más lúcidos sobre la naturaleza y la forma de las relaciones de fuerza literarias" (Casanova, 2001, p. 65).

2 “... lo que mas le molesta es que las nuevas reflexiones sobre la posmodernidad - y todos sabemos a qué textos se refieren todos - no incluyan sus propias reflexiones sobre el fin de la modernidad. Una vez más, vemos a un Paz que discute con un discurso europeo, o eurocéntrico, que de forma deliberada deja fuera a obras como la suya, que proviene de un escritor latinoamericano marginado. Se ve a sí mismo de nuevo excluido de esa clase de discusión que supuestamente incluye reflexiones de la periferia, pues si hay algo que deba caracterizar a los posmoderno es un reconocimiento amplio de un mundo policéntrico" (Santí apud Grenier, 2004, p. 150-151).
} 
del peso específico que la consolidó como referencia ineludible en América Latina sobre tales asuntos. Otro derrotero fue el que siguió su profunda e históricamente precoz reflexión sobre la modernidad. Si Paz fue citado ampliamente para abastecer los discursos contra el socialismo, el marxismo y las sociedades totalitarias, no sucedió lo mismo con sus trabajos sobre la modernidad. A pesar que desde hace apenas unos lustros el tema se ha puesto en boga en las discusiones políticas, filosóficas y culturales, los trabajos de Paz brillan por su ausencia en dicho concierto. ${ }^{3}$ Incluso, no es extraño encontrar en diversos autores claves, cuyos textos se han convertido en obras axiales para aspectos específicos de las actuales reflexiones sobre la modernidad, ideas y descubrimientos que Octavio Paz avanzó hace ya décadas. ¿Cuál es la razón de ese desconocimiento y ninguneo que padeció y sigue padeciendo esta faceta de la obra de nuestro poeta?

Las causas del desdén están en lo ya señalado más arriba, a saber:

a) el sentido de que dicha obra es la reflexión de un poeta, un "simple poeta", y no un filósofo o cientista social, ${ }^{4} \mathrm{y}$

b) él era un poeta de las afueras de la modernidad.

Con ello una crucial paradoja asoma la cabeza: la razón, al institucionalizarse, construye los mecanismos y discursos para avalar todo aquello que pretenda acceder a alcanzar el reconocimiento de saber verdadero. Las explicaciones que no cumplan con las reglas establecidas por la razón devenida en discurso científico, no lograrán hacerse merecedoras de su aval y serán expulsadas hacia los nebulosos reinos de lo mítico y lo poético donde lo "real", "verdadero", "objetivo", "racional", etc. no tiene cabida. La crítica, elemento inherente al ejercicio de la razón, es abandonada cuando ésta se ve en el espejo de sus propios postulados. Al renunciar al ejercicio básico de su propia historización, la razón crítica termina por cerrar las puertas a otras formas de entender la realidad, a otras formas de conocimiento, a otras formas de concebir y comprender el mundo, negándose entonces a sí misma.

Así, la reflexión de un poeta no merece mayor atención y peor aun si la voz del poeta viene desde los extraños y alejados rumbos de la periferia cultural. Paz fue un poeta nacido en México, es decir en Latinoamérica, una de las regiones que por definición misma de la modernidad es parte constitutiva

3 De los teóricos sobre la modernidad y posmodernidad avalados por el stablishment académico únicamente Jürgen Habermas hace una mustia referencia al poeta mexicano (Habermas, 1989). (Hay versión en línea de esa parte del texto en: <http://www.enfocarte.com/1.9/filosofia.html>, 14 septiembre 2011.)

4 "Primero y antes que otra cosa, Paz era un poeta y, por definición propia, un poeta que escribía dentro de la tradición romántica" (Brading, 2002, p.19). 
de los suburbios de la civilización. Definidas las relaciones de poder de la república mundial de las letras, es muy difícil que la metrópoli cultural acepte y valore que desde las afueras se expresen reflexiones que ayuden a entenderla a sí misma.

Y justo por todo lo anterior se constituye otra gran paradoja, pues precisamente porque Paz fue un poeta latinoamericano es por lo que él tuvo la posibilidad, mejor dicho la sensibilidad, para avanzar en develar el significado de la modernidad mucho tiempo antes que los autores europeos tan referidos en los últimos veinte años. La relación del poeta con el lenguaje, su forma de entender a las palabras y a los conceptos es lo que le permitió comprender a cabalidad la existencia y el significado de ese punto negro en el sol del que habló Nerval:

El escritor es el hombre que ve en todas las cosas, aún las más nítidas, un diminuto punto negro. Nerval lo dice de modo admirable: "ví al sol y un point noir est resté dans mon regard avide". El punto negro es la conciencia o, más exactamente, el sentimiento de la general relatividad de las cosas. El punto negro provoca la distancia de la realidad y se expresa en dos direcciones opuestas aunque con frecuencia complementarias: la crítica de la realidad y la invención de otras realidades (Paz, 2001c, p. 145).

El ser poeta le permitió tomar distancia de la realidad y comprender que las verdades son relativas y construidas. La poesía lo proveyó de la posibilidad de concebir y entender que las palabras son tan sólo metáforas de la realidad. Al ser poeta, es decir, al vivir y ejercitarse en la libertad que la poesía significa para el uso del lenguaje, Paz fue capaz de concebir y crear olmos que dieran peras, cuestión inimaginable desde la racionalidad de la agronomía o de la botánica. Las palabras, los conceptos, no son las cosas, el poeta al nombrar al mundo lo crea. La comprensión de la libertad de las palabras frente a la realidad le permite al poeta visualizar ese punto negro en el sol representativo de la "general relatividad de las cosas", entre ellas cualquier verdad (Paz, 1999, p. 61ss). La posibilidad y necesidad ineludible de dejar caer una gota de duda sobre toda las certezas proviene al final de las cuentas de la aceptación de que las palabras - los conceptos - no son las cosas, por lo cual siempre existe la posibilidad de que todo sea diferente, de que exista otra manera de entender, comprender y concebir al mundo.

Desde la poesía - y por la poesía - Paz empezó a visualizar otros sentidos, otras formas explicativas de la realidad toda. Por ser poeta Paz fue capaz de ver y reconocer la existencia de la otredad elemento fundamental en la reflexión 
sobre la modernidad, pero este sentido poético habría de completarse con un segundo elemento constitutivo de su profunda reflexión sobre la otredad: el ser mexicano. ${ }^{5}$

En 1937, al vivir una impactante anécdota en la ciudad universitaria de Madrid, Paz súbitamente se dio cuenta de que los otros, los diferentes, eran seres humanos iguales a "nosotros" (Paz, 1998, p. 446).

El impacto del descubrimiento sobre la forma humana en la que la otredad podía encarnar provocó que el joven poeta empezara entonces a preguntarse en qué consistía la diferencia, esto es, cómo estaba constituida esa otredad. La construcción de una respuesta habría de marcar toda su obra futura. Dos años antes de su muerte, en la última entrevista que concedió, Octavio Paz explicitó la trascendencia de la otredad en su obra:

La política es el arte de convivir con los otros. Todos mis escritos están en relación - incluso en convivencia - con lo que a veces se llama la otredad. En mis poemas más íntimos, en los que hablo conmigo mismo, hablo con el otro que soy; en mis poemas eróticos, con la otra; en mis escritos en los que toco temas de religión, metafísica o filosofía, interrogo a lo Otro. Los hombres y las mujeres vivimos siempre con los otros y ante lo Otro. Esto y aquello: pertenecemos a dos mundos distintos e inseparables (Peralta, 1996, p. 168-169).

Si lo poético es un factor fundamental para explicar el sentido de la reflexión paciana, otro eje igualmente importante es el hecho de él haber sido Latinoamericano. Plantear estas cuestiones desde nuestra región (histórica, cultural) le imbuyó a su reflexión un matiz que sólo la convivencia diaria, cotidiana e históricamente construida con la otredad podría haberle otorgado. Para los latinoamericanos no sólo la otredad configura nuestro horizonte cotidiano, sino que nosotros mismos, a su vez, constituimos la otredad vistos desde la modernidad. Concebida bajo este ambiente dual es por lo que la disertación de Paz sobre la modernidad y la otredad habría de adelantarse por lo menos un cuarto de siglo a su aparición y puesta en boga en las metrópolis culturales.

Vista desde la modernidad, Latinoamérica es uno de tantos otros mundos. Gabriel García Márquez ha explicado que la tarea más difícil para los escritores latinoamericanos no es imaginar realidades creíbles sino, más bien,

\footnotetext{
5 "La poesía nos hace tocar lo impalpable y escuchar la marea del silencio cubriendo un paisaje devastado por el insomnio. El testimonio poético nos revela otro mundo dentro de este mundo, el mundo otro que es este mundo. Los sentidos, sin perder sus poderes, se convierten en servidores de la imaginación y nos hacen oír lo inaudito y ver lo imperceptible" (Paz, 1996a, p. 213).
} 
hacer creíble la realidad en la que vivimos. Esta idea sintetiza la otra parte de la explicación sobre por qué Paz, un poeta de los suburbios de la modernidad, fue capaz de pensar con muchísima anticipación problemas que los propios intelectuales europeos tardaron varias décadas en siquiera concebir. La otredad ha estado aquí, nosotros siempre hemos sido los otros y, a su vez, en este nosotros hemos vivido siempre con los otros. Paz lo identificó de forma muy clara cuando al indagar sobre quiénes somos nos observó desde un poco más lejos. Una vez que empezó a andar el camino descubierto con El laberinto de la soledad nunca más se alejó de él. En su explicación sobre el ser mexicano encontró a los otros y, en consecuencia, comenzó a entender el sentido de nosotros.

La otredad se convirtió en el punto nucleador, en el eje analítico desde el cual Paz se pensó como poeta, como escritor y como intelectual latinoamericano. Es por demás significativo que en lejano año de 1949 Paz eligiera como epígrafe para el que a la sazón se convertiría en uno de los textos emblemáticos de su obra unas líneas de un poeta -ijustamente de un poeta!acerca de la otredad. En la primera página de El laberinto de la soledad, el lector encuentra el siguiente párrafo de Antonio Machado:

Lo otro no existe: tal es la fe racional, la incurable creencia de la razón humana. Identidad = realidad, como si, al fin de cuentas, todo hubiera de ser, absoluta y necesariamente, uno y lo mismo. Pero lo otro no se deja eliminar; subsiste, persiste; es el hueso duro de roer en que la razón se deja los dientes. Abel Martín, con fe poética, no menos humana que la fe racional, creía en lo otro, en "La esencial Heterogeneidad del ser", como si dijéramos en la incurable otredad que padece lo uno.

"La incurable otredad que padece lo uno." A pesar de que la modernidad bajo la máscara de la fe racional desaparece en el aire todo lo existente, la otredad ahí está, se mantiene siendo parte de uno mismo. La otredad es inconcebible si se carece de la maleabilidad de espíritu, la apertura de juicio, la capacidad de ser total y completamente consecuente en el ejercicio de la crítica la cual, no debiera olvidarse, constituye la bandera intelectual levantada por la propia racionalidad moderna. La otredad, en efecto, es "el hueso duro de roer", es la realidad que a pesar de su negación seguirá estando ahí una vez diluida la niebla de las ideologías, de la modernidad como forma única y exclusiva de desarrollo, de la vinculación del progreso a una noción unívoca de futuro, de la instauración de una sola concepción del tiempo como la única y hegemónica. La otredad finalmente ahí está, recordándonos que el mundo no es tan sencillo 
ni unilineal como se nos presenta y explica desde la modernidad, que el tiempo no es uno exclusivamente y que para entenderlo, concebirlo y asumirlo es necesario criticar todo, empezando por el propio juicio crítico, es decir, es necesario historizar a la propia historia. De ahí que para comprender en dónde estamos, para percibir nuestro rol histórico, debemos saber escuchar a la otra voz o, mejor dicho, a las otras voces.

En El laberinto... Paz descubrió la otredad a sus lectores, desveló su existencia en nuestro presente. ${ }^{6}$ Encontró que la historia de México ha sido una larga lucha por negar, ocultar y enmascarar a la otredad. El poeta se adelantó medio siglo y señaló los derroteros por los cuales habríamos de caminar en las futuras discusiones sobre el multiculturalismo y el interculturalismo. La visión de la historia que plantea Paz, a la cual casi veinte años después en Posdata (1969) llevaría a una posición más radicalizada y comprometida con el concepto de democracia, fue profundamente provocadora pues apareció justo cuando en nuestro país se vivía la borrachera por el progreso, por el desarrollo, por correr de manera desbocada en la búsqueda de llegar al mañana.

Al principio de la década de los cincuenta México se había entregado a la desaforada carrera por alcanzar un futuro que por definición era inasible. Para avanzar hacia ese porvenir igualado a conceptos como desarrollo, crecimiento y progreso, el pasado resultaba un lastre del cual era necesario deshacerse o, por lo menos, intentar esconderlo bajo la alfombra del discurso histórico político hegemónico. Paz colocó los cimientos para romper la univocidad de la historia oficializada pues con su ensayo levantó el tapete bajo el cual se pretendía ocultar a los otros Méxicos; con ello el poeta mostró que esos pasados no solamente ahí seguían sino que eran elementos axiales para la comprensión de nuestra identidad.

Avanzar, como lo hizo Paz en 1949, en el aquilatamiento y la admisión de la existencia de distintas culturas, de distintos grupos sociales que no necesariamente comparten una apreciación sobre lo que nos define, fue adelantarse por varias décadas en la concepción y comprensión de los temas que hoy en día están presentes con mayor asiduidad en la reflexión sociopolítica expresada en las discusiones sobre universalidad, pluralidad, tolerancia, interculturalidad y al más general de la democracia. Varias décadas después, ya hacia el final de su vida, el poeta escribió:

\footnotetext{
6 "Universalidad, modernidad y democracia son hoy términos inseparables. Cada uno depende y exige la presencia de los otros,. Éste ha sido el tema de todo lo que he escrito sobre México desde la aparición de El laberinto de la soledad" (Paz, 2001a, p. 31).
} 
Queremos ser universales, pero el único modo de serlo es mantenernos fieles a nuestras propias emociones, a nuestra propia visión de la vida, y en este sentido somos particulares. [...] En sentido político, sabemos también que a fin de alcanzar una comprensión del mundo, debemos comprender a los demás. Finalmente la política encontró a la democracia. Tolerancia: aceptación de la existencia de los demás (Paz et al., 1996, p. 11).

Como hemos visto, el tema de la relativización de nuestras certezas y la apertura hacia el reconocimiento de otras formas de concebir al mundo no es fácil de concebir y mucho menos de asumir. Su complejidad significa, entre otras cosas, un punto cardinal: la dificultad en la aceptación de la existencia de otro equiparable en valor y valores a los de uno mismo. Sin embargo, esta faceta del asunto se complementa con un tema quizá aún más problemático, me refiero al encarnado en la actual discusión sobre el pluralismo y la tolerancia. ¿Cómo es ello? Quiere decir que al reconocer al otro estaremos reconociéndonos a nosotros mismos. Concebir la existencia del otro es avanzar en la comprensión y admisión de nuestra propia historicidad. Si el otro existe y con él ciertos valores frente a la vida, la muerte, el amor, la educación, el progreso, en fin frente a todo lo que es su existencia, ello posibilita que nosotros mismos nos percatemos de los límites históricos, geográficos, políticos, en suma, culturales de nuestro propio sistema de valores. Frente al otro nos definimos y éste, a su vez, nos define y se define a sí mismo frente a nosotros.

En el interior de la identidad, aparece la otredad. La diferencia no está afuera en los muchos, sino dentro, en el uno. La contradicción es más grave que la que opone el uno al muchos además, parece insuperable: el ser es otro del que es. La identidad no se rompe o dispersa: ella misma es dualidad pues, sin dejar de ser lo que es, también es otra. [...] La otredad es otra cosa: es la diferencia dentro de la identidad. La unidad no se dispersa ni se derrama: cerrada en sí misma, encerrada, contiene a su contrario. No al no-ser sino al otro (Paz, 1996b, p. 29-30).

Llegados a este punto de análisis es necesario hacer referencia aunque sea en unas cuantas palabras una idea fundamental que Paz delineó y abonó a la largo de su amplia obra ensayística. Dentro de la lógica promoderna, proprogreso, profuturo, los grupos sobrevivientes del pasado que nos evidencian nuestro ser mestizo, lejos de ser valorados como factores de distinción, valor o riqueza cultural que han aportado su perfil para la constitución de nuestra identidad nacional, son vistos como un auténtico lastre que nos ha impedido alcanzar los niveles de desarrollo que debiéramos. En otras palabras, se 
constituye la convicción de que la historia universal nos habría apartado un lugar protagónico en sus libros, de no ser por la mala suerte de contar en la construcción de nuestra propia historia particular con tales grupos sociales atávicos que nos amarran a la premodernidad, al atraso, al desfase histórico.

Así empezamos a entender el trágico y aparentemente incomprensible hecho de que en nuestro tiempo presente al indio muerto se le vanaglorie, mientras al indio vivo se le vitupera y defenestra. El indio desterrado al pasado es útil para darnos elementos positivos de identidad, ya que la existencia de aquellas grandes civilizaciones "prehispánicas" son motivo de orgullo y reconocimiento; sin embargo, los descendientes directos de aquellos grupos étnicos, los indios vivos del presente, ya no son vistos como el reflejo de un pasado glorioso, sino más bien ellos encarnan en la representación viva de un presente de atraso que nos imposibilita alcanzar el futuro al que estaríamos designados. Se reproduce así en México un fenómeno a primera vista incomprensible e inconcebible desde el punto de vista de la historia nacionalista: el racismo sobre sus indios.

Más de treinta años después de escrito El laberinto... Paz regresaría al mismo tema abierto desde entonces: "El mundo indio fue desde el principio el mundo otro, en la acepción más fuerte del término Otredad que, para nosotros los mexicanos, se resuelve en identidad, lejanía que es proximidad" (Paz, 1997b, p. 305).

Acercarse al estudio de la historia (en general) asumiendo este marco conceptual donde la otredad juega un rol fundamental, fue abrir las puertas de par en par a las nociones que posteriormente habrían de denominarse interculturales y/o multiculturales. En 1950 evidenciar - como lo hizo Paz - la existencia de una sola voz en la conformación de nuestras certidumbres sociales, políticas, históricas, etc., significó el trastocamiento radical de los elementos ideológicos constitutivos de la concepción hegemónica de concebirnos a nosotros mismos, a nuestra cultura, al mundo y, en una palabra, a la propia historia.

A mediados del siglo pasado Octavio Paz, un intelectual latinoamericano, un poeta mexicano, con su reflexión crítica sobre la manera en que la historia fue definiendo y construyendo los rasgos esenciales que habrían de identificarla al verse en el espejo, abonó el terreno para el cabal desarrollo y comprensión de la crítica surgida posteriormente desde el mismo interior de la historiografía occidental (cf. p. ej. De Certeau, 1995, p. 69).

El esfuerzo por concebir a la otredad y comprenderla como algo que no sólo existe fuera de nosotros sino que es a partir de ella como definimos nuestro propio sentido de existencia es complicado tanto a nivel personal, más cuanto 
social e histórico. Significa asumir desde la raíz y en todas sus consecuencias la necesidad de relativizar (historizar) nuestra vida, convicciones y certidumbres, en aras de poder ubicarlas en sus justos e históricos términos, lo cual no es otra cosa que abrirnos a la existencia de otras formas de entender y concebir la vida, la historia, el tiempo, el mundo, etc., a las cuales no solamente tendríamos que "respetar" y "tolerar", sino asumir como elementos enriquecedores, valorizadores y potenciadores de nuestra propia vida, existencia e historia. En síntesis, la otredad nos constituye en nuestra mismidad.

Desde la lógica cientificista impuesta por la modernidad creemos y estamos convencidos de que sólo existe un camino. La posibilidad de visualizar, entender y asumir la otredad tendría entonces que venir desde afuera de esos cánones. Paz arribó desde la poesía, no podía ser de otro modo. La libertad por antonomasia que la concepción del lenguaje a la que se sumó Paz otorga al acto poético, fue la que le hizo posible visualizar y comprender la otredad. Por ello es que fueron esos cuantos renglones escritos por otro poeta hablando sobre la otredad, los que él eligió para recibir a los lectores en El laberinto... Insisto: comprender y aceptar el sentido profundo que significa la otredad no es fácil, el mundo en el que nos creamos y al cual recreamos nos hace estar convencidos de que el nuestro (plano, unilineal, unidireccional y unívoco) es el único existente, y a él pretendemos integrar toda la realidad. El poeta nos empezo a mostrar que esa realidad no es una ni única; al contrario, es múltiple, diversa y tan sólo una entre la infinidad de formas de verla y de asumirla.

Es necesario entonces simplemente darnos cuenta de que existen otras realidades. Concebir su existencia es el primer paso, pero después resta lo más difícil: entenderlas por sí mismas, respetarlas y, finalmente, comprender y asumir que la convivencia con ellas es un filón para el enriquecimiento mutuo. Mientras no asumamos lo anterior seguiremos debatiéndonos en el esfuerzo de integrarlas a nuestra realidad, hacerlas partícipes de nuestra loca carrera hacia el futuro que, por definición, es inalcanzable; las seguiremos viendo a través del tamiz del progreso y, por tanto, la seguiremos excluyendo por ser "arcaicas" y/o diferentes.

Se evidencia entonces la imperiosa necesidad intelectual de ubicar históricamente (historicizar) la concepción de la historia que tradicionalmente se ha establecido como hegemónica. Este ejercicio necesariamente desembocará en renunciar a la convicción sobre la existencia de una homogeneidad ahistórica de la humanidad, es decir, abandonaremos nociones como "universal", "nacional", etc. que de suyo eliminan, ocultan o simplemente son incapaces de ver y asumir la posibilidad de la existencia de otras formas distintas a la instaurada hegemónicamente para entender al mundo y su devenir. 
Ahora bien, a partir de la Ilustración se instauró la noción de la existencia de representaciones de la realidad superiores e inferiores. ¿Cómo y por qué se definió esa superioridad? Evidentemente todas las discusiones sobre el sentido de la propia existencia de la realidad, de la cientificidad de los diversos métodos para la comprensión de la realidad etc., es tan añeja como vasta la bibliografía respectiva. La Ilustración generó un discurso específico (la ciencia) que se hizo hegemónico con el cual se califica, aprueba y se expiden o niegan certificados de veracidad a las expresiones que pretendan explicar la "realidad".

No sólo los discursos y sus métodos se hicieron hegemónicos, también - obviamente - los conceptos. Se universalizan (gracias a una hegemonía política, económica y cultural) nociones que debieran ser particulares. El poder definió la validez de tales expresiones, con lo cual el discurso que debía ser crítico a ultranza renunció de facto a tal ejercicio definitorio. La trágica paradoja se concretó: la crítica fue eliminada por la hegemonía cultural que enarbolaba a la misma crítica como su bandera. La historia se deshistorizó. Paz, seis años después de El laberinto..., escribió una idea que, con ajustes y pulimentos, él habría de mantener hasta el final de sus días:

[...] si ha de surgir un nuevo pensamiento revolucionario, tendrá que absorber dos tradiciones desdeñadas por Marx y sus herederos: la libertad y la poética, entendida esta última como experiencia de la otredad, no es menos cierto que ese pensamiento, como el marxismo, será crítico y creador; conocimiento que abraza a la sociedad en su realidad concreta y en su movimiento general - y la cambia. Razón activa (Paz, 1999, p. 305).

La historia (y la sociología) definida como ciencia con todo y las múltiples (y en buena medida desde esta perspectiva bizantinas) discusiones sobre su estatuto epistemológico, es heredera de las nociones que ven a la ciencia como el único mecanismo, discurso, método o como se le quiera denominar a través del cual el ser humano es capaz de vislumbrar, conocer, aprehender a la realidad, la cual a su vez es entendida de una sola manera, la que le permite ser desmenuzada, analizada y comprendida por el sujeto que sea capaz de utilizar los métodos y protocolos apropiados. Es de sobra conocido que las ciencias sociales vienen a ser algo así como los hijos entenados del afán y obsesión científica por comprender la realidad (en este caso social), por lo que todas ellas (historia, sociología, política, economía, etc.) debieron nacer y constituirse con el estigma de ser cuestionadas sobre su propio sentido de existencia. De ahí que ellas se hayan dado a la tarea de construirse las coartadas epistemológicas más abigarradas y absurdas para hacer que sus 
respectivos objetos de conocimiento pudieran ser catalogados como proclives a ser estudiados "científicamente". Estos desesperados intentos por tratar de ajustar la reflexión sobre los fenómenos sociales a los parangones instituidos por la ciencia han hecho caso omiso de una cuestión básica que jamás debió olvidarse: los métodos de análisis que la ciencia ideó e instituyó fueron pensados para el abordaje específico de objetos de estudio perfectamente definidos que cumplían a cabalidad con el sentido de realidad necesario para ser abordados de esa forma. Así, desde las nociones que se han construido para explicar a una historia específica, se trata de ver y entender a todo el conjunto mundial. Los lentes construidos por esa historia se erigen en los miradores desde los cuales se lee la historia de todos.

Frente a conceptos del tipo de "mundial", "universal", habría que plantear - nos recordó Paz - la particularidad. El tiempo, la manera de concebirlo, es un concepto nodal. La modernidad instauró una concepción lineal del tiempo (pasado-presente-futuro) en la cual el futuro es sinónimo de cambio y este a su vez de progreso. Ello ocasionó que el mundo se haya dividido únicamente en dos: lo moderno y lo antiguo; este último es el epíteto endilgado a todas aquellas sociedades que no comparten las ideas e instituciones modernas. Al dividirse al mundo en desarrollado y subdesarrollado se logró lo imposible: unir en un concepto una multiplicidad de realidades, integrar en una misma definición a multitud de culturas. Luego entonces, es necesario identificar este ardid hegemónico cultural y explicitar una vez más que no existe una sola y única civilización desde la cual se pueda evaluar, calificar, criticar el nivel de progreso alcanzado por otras o, peor aun, cómo esa otra se delinea y se ve únicamente desde esta voz (el progreso) que se ha instituido como la hegemónica. De hecho, en ninguna cultura el desarrollo es lineal, lo cual significa en otras palabras que la historia ignora la línea recta.

La temporalidad universal que postula la modernidad provoca que esta noción sea única y exclusivamente característica de Occidente. Casi medio siglo después de haber escrito El laberinto... Paz publicó la siguiente reflexión que pareciera referirse a lo que él había ayudado a descubrir con aquel emblemático ensayo:

México buscaba al presente afuera y lo encontró adentro, enterrado pero vivo. La búsqueda de la modernidad nos llevó a descubrir nuestra antigüedad, el rostro oculto de la nación. Inesperada lección histórica que no sé si todos han aprendido: entre tradición y modernidad hay un puente. Aisladas, las tradiciones se petrifican y las modernidades se volatilizan; en conjunción, una anima a la otra y la otra le responde dándole peso y gravedad (Paz, 1997a, p. 36-37). 
La instauración del futuro como el tiempo al cual debemos inexorablemente llegar y hacia el cual están encaminados todos y cada uno de los esfuerzos humanos, ha hecho que cuando este futuro ha sido cuestionado o se han cerrado las puertas para acceder a él, toda la cultura moderna entre en crisis, su objetivo deja de existir y la civilización se debata en lo que se puede denominar una crisis de identidad en donde todas sus creencias acerca de la evolución y el progreso son negadas y cuestionadas, ya que el principio que funda a nuestro tiempo no es una verdad eterna, sino la verdad del cambio.

Latinoamérica y con ella México - escribió Paz - se apropió de la filosofía política francesa, inglesa y estadounidense, de las ideas de la modernidad. La filosofía política de la modernidad fue adoptada pero no adaptada a nuestros países, por lo que nuestra historia es una historia excéntrica. La modernidad específicamente para nuestros países no debe referirse a patrones cuantitativos de desarrollo, sino que debe encaminarse hacia la capacidad de crítica y autocrítica de la sociedad en búsqueda de una forma moderna acorde a nuestras historias y formas de ser. De cara a este panorama es necesario reconocer nuestra pluralidad de culturas y civilizaciones y la pluralidad de tiempos históricos que ello significa, para afrontar la concepción lineal y unívoca del tiempo característica a la modernidad.

Debemos volver los ojos a nuestra otredad, nuestra historia no empezó hace quinientos años y aún está lejos de terminar. Siguiendo esta línea reflexiva, por ejemplo, la conquista se piensa como un cambio de civilización, debido a ello es por lo que desde entonces México vio al mundo prehispánico como el otro mundo, el otro lado. Debemos reflexionar sobre este aspecto. La historia de México no puede ser pensada de forma simple y llanamente lineal. Es cierto, en ella existe continuidad pero es un craso error considerarla exclusivamente de manera lineal, unidireccional, más bien debiéramos pensarla como una serie de yuxtaposiciones de sociedades distintas. Lo intercultural para el análisis histórico de nuestro país radica justo en este punto: el reconocimiento de la otredad, concepto propuesto por Paz para nuestra propia comprensión - es necesario repetirlo cuantas veces sea necesario - desde 1950.

La otredad, sin duda, fue el elemento que signó la totalidad de la obra de Octavio Paz. Él más que nadie lo tenía perfectamente claro, reconociendo y valorando a cabalidad los horizontes que ella le impregnó a su reflexión. La otredad como astrolabio para surcar los mares de la crítica. La posibilidades de asumir este concepto como guía en la búsqueda de respuestas a las preguntas sobre quiénes somos y hacia dónde vamos es la clave de la crítica cualquiera que fuera su objeto de análisis. La crítica no se circunscribe al sentido más amplio (social) de las cuestiones, empieza en el más íntimo, particular y 
cercano: el yo primero, la mismidad del ser en su vida cotidiana que permea y es permeada por una infinita variedad de factores. En un comentario hecho a Enrico Mario Santí, Paz apuntó que la otredad "designa a la vida diaria, la de todos los días, en su radical extrañeza.". Se trata, por tanto, de la experiencia de "estar en el mundo", es decir, "de estar aquí y ahora [...] La otredad es el manantial perenne de la poesía y, asimismo, de la novela y el teatro; es la vida misma" (Santi, 1997, p. 307).

Desde el mirador constituido por la otredad, el mundo se ve y es distinto. Sólo desde ahí se puede tener una panorámica lo suficientemente amplia y rica para comprender que la duda, la interrogación, es la pócima de la cual deberemos verter unas gotas sobre todo, absolutamente todo, lo que conforma nuestro universo, empezando en primerísimo lugar por el yo individual que cada uno de nosotros es y las certezas que ese yo ha construido. La riqueza de la crítica habita en muchos lados, más que tan sólo en aquellos institucionalmente reconocidos como tales, y uno de los principales deberes del espíritu intelectual es ser lo suficientemente flexible para reconocerlos y actuar en consecuencia.

La otredad nos define. Nosotros somos los otros. A finales de 1993 Octavio Paz, el poeta, a punto de cumplir ochenta años, publicó simultáneamente dos libros. Uno, Itinerario, fue un acercamiento a un primer y somero balance de lo que podría ser su autobiografía intelectual, sellada y definida - como hemos visto - por el descubrimiento y reconocimiento de la otredad. El segundo, La llama doble, cerraba la pinza sobre el significado y la importancia de este concepto en la definición y comprensión del mundo a partir de la vida más inmediata del individuo. No bastaba con transformar al mundo, había que explicarlo desde sus cimientos más particulares.

Los hilos conductores de la reflexión paciana en La llama doble eran ni más ni menos que el amor y el erotismo. El primero, ansia de completud, gran apuesta que nadie está seguro de ganar porque es un envite que depende de la libertad del otro. El segundo, "es ante todo y sobre todo sed de otredad" (Paz, 1996a, p. 220).

El amor, bisagra utilizada por el poeta para unir a las dos grandes nociones: libertad y otredad. Hacía el final de su vida Paz terminaba de trazar el círculo. Lo otro continuaba siendo el hueso duro de roer en que la razón se deja los dientes. Lo que había empezado con El laberinto... encontró un posible cierre en la reflexión sobre el amor y el erotismo, pues ambos conceptos conllevan a la comprensión de la existencia del individuo siempre en función de la aparición y el respeto por el otro. Respeto en primerísimo lugar de su libertad. Nuestra ansia de completud depende del acuerdo con 
el otro, de asumir su libertad de aceptar o rechazar nuestra solicitud de reciprocidad. $^{7}$

El otro requiere reconocimiento de su existencia y, fundamentalmente, aceptación de su libertad, sólo así puede constituirse en parte integrante del nosotros. La otredad encarnada en la pareja amorosa. Por ello es que el amor es la gran subversión moderna:

El amor ha sido y es la gran subversión de Occidente. Como en el erotismo, el agente de la transformación es la imaginación. Sólo que, en el caso del amor, el cambio se despliega en relación contraria: no niega al otro ni lo reduce a sombra sino que es negación de la propia soberanía. Esta autonegación tiene una contrapartida: la aceptación del otro. Al revés de lo que ocurre en el dominio del libertinaje, la imágenes encarnan: el otro, la otra, no es una sombra sino una realidad carnal y espiritual. Puedo tocarla pero también hablar con ella. Y puedo oírla - y más beberme sus palabras. Otra vez la transubstanciación: el cuerpo se vuelve voz, sentido; el alma es corporal. Todo amor es eucaristía (ibid., p. 288).

La otredad encarna en la pareja amorosa. El poeta Octavio Paz arribó una vez más a este puerto cuando ya contaba con ochenta años de edad. El periplo iniciado hacia finales de la década de los cuarenta del siglo pasado llegaba a su fin. La otredad lo había provisto para ser capaz de ver de otras formas nuestra historia tanto social como individual. La otredad, piedra de toque del pensamiento y la obra paciana. La otredad contemplada y registrada por el poeta varias décadas antes que filósofos y cientistas sociales. Al final de su vida Paz enfatizaba de nueva cuenta la necesidad urgente de historizar nuestras certezas, de asumir la existencia de infinidad de tiempos. Ahora el amor le servía a manera de vidrio polarizado para distinguir las huellas de la otredad, para poder reconocer la presencia de diversos tiempos y con ello cuestionar, historizar, combatir la noción unilineal impuesta por la modernidad. ${ }^{8}$ Recién escrito lo anterior me apresuro a matizar: Paz no arribó a dicho puerto, más

\footnotetext{
7 "La exclusividad requiere la reciprocidad, el acuerdo del otro, su voluntad. Así pues, el amor único colinda con otro de los elementos constitutivos: la libertad. [...] El verdadero amor consiste precisamente en la transformación del apetito de posesión en entrega. Por esto pide reciprocidad y así trastorna radicalmente la vieja relación entre dominio y servidumbre" (ibid., p. 284).

8 "El amor no vence a la muerte: es una apuesta contra el tiempo y sus accidentes. Por el amor vislumbramos en esta vida, la otra vida. No a la vida eterna sino [...] a la vivacidad pura. [...] Reconciliación con la totalidad que es el mundo. También con los tres tiempos. El amor no es la eternidad; tampoco es el tiempo de los calendarios y los relojes, el tiempo sucesivo. El tiempo del amor no es grande ni es chico: es la percepción instantánea de todos los tiempos en uno solo, de todas las vidas en un instante [...]" (ibid., p. 352).
} 
bien lo construyó como punto de partida y eterno retorno de toda su reflexión, pues constituyó el elemento aglutinador de su obra poética y sirvió, además, para otorgarle sentido y anclaje a conceptos como libertad, amor, crítica, tiempo y modernidad.

Paz lo tenía perfectamente claro, tanto así que en uno de sus poemas más representativos escribió algunos versos que habrían de servir (tendrían que hacerlo) de guía para nuestro imperecedero andar en busca de nosotros mismos:

los otros todos que nosotros somos-, soy otro cuando soy, los actos míos son más míos si son también de todos, para que pueda ser he de ser otro, salir de mi, buscarme entre los otros, los otros que no son si yo no existo, los otros que me dan plena existencia (Paz, 2001b, p. 231)

\section{Referencias}

BRADING, David. Octavio Paz y la poética de la historia mexicana. México: Fondo de Cultura Económica, 2002.

CASANOVA, Pascale. La república mundial de las letras. Barcelona: Anagrama, Colección Argumentos 258, 2001.

DE CERTEAU, Michel. Historia y psicoanálisis. México: Universidad Iberoamericana, 1995.

GRENIER, Yvon, Del arte a la politica: Octavio Paz y la búsqueda de la libertad. México: Fondo de Cultura Económica, 2004.

HABERMAS, Jürgen, El discurso filosófico de la modernidad. Madrid: Taurus, 1989.

PAZ, Octavio, El arco y la lira. Obras Completas, tomo 1. México: Fondo de Cultura Económica, 1999, p.33-288.

. El lugar de la prueba. Discurso inaugural del Congreso Internacional de Escritores, celebrado en conmemoración del Segundo Congreso Internacional de Escritores Antifascistas de julio de 1937. Obras Completas, tomo 9. México: Fondo de Cultura Económica, 1998, p.438-446.

. Entrada retrospectiva. Obras Completas, tomo 8. México: Fondo de Cultura Económica,., 2001a, p.15-32.

. La búsqueda del presente (Conferencia Nobel, 1990). Obras Completas, tomo 3. México: Fondo de Cultura Económica, 1997a, p. 31-41.

. La llama doble. Amor y erotismo. Obras Completas, tomo 10. México: Fondo de Cultura Económica, 1996a, p. 209-352. 
PAZ, Octavio, La tradición liberal. Obras Completas, tomo 3. México: Fondo de Cultura Económica, 1997b , p. 303-307.

Nosotros: los otros. Obras Completas, tomo 10. México: Fondo de Cultura Económica, 1996b, p. 15-36.

Piedra del sol: libertad bajo palabra Obras Completas, tomo 11. México: Fondo de Cultura Económica, 2001b, p. 21-233.

. Silueta de Ireneo Paz. Obras Completas, tomo 14. México: Fondo de Cultura Económica, 2001c, p. 141-149.

PAZ, Octavio et al. Particularismo, universalismo y literatura. Vuelta, México, v. 20, n. 235, jun. 1996.

PERALTA, Braulio. El poeta en su tierra: diálogos con Octavio Paz. México: Grijalbo, 1996.

SANTI, Enrico Mario. El acto de las palabras: estudios y diálogos con Octavio Paz. México: Fondo de Cultura Económica, 1997.

Recebido em: 17.10.2011

Aprovado em: 29.12.2011 